\title{
A QGIS Based Workflow for Optimized Cable Road Layout Planning ${ }^{\dagger}$
}

\author{
Leo Gallus Bont ${ }^{1, *}$, Laura Ramstein ${ }^{1}$, Janine Schweier ${ }^{1}$ and Hans Heinimann ${ }^{2}$ \\ 1 Swiss Federal Institute for Forest, Snow and Landscape Research (WSL), Sustainable Forestry Group, \\ Zuercherstrasse 111, CH 8903 Birmensdorf, Switzerland; laura.ramstein@wsl.ch (L.R.); \\ janine.schweier@wsl.ch (L.S.) \\ 2 Swiss Federal Institute of Technology Zurich (ETH Zuerich), Zürich 8092, Switzerland; \\ hans.heinimann@env.ethz.ch \\ * Correspondence: leo.bont@wsl.ch \\ † Presented at the 1st International Electronic Conference on Forests -Forests for a Better Future: \\ Sustainability, Innovation, Interdisciplinarity, 15-30 November 2020; Available online: \\ https://iecf2020.sciforum.net.
}

Citation: Bont, L.G.; Ramstein, L.; Schweier, J.; Heinimann, H. A QGIS Based Workflow for Optimized Cable Road Layout Planning. Environ. Sci. Proc. 2020, 3, 103. https://doi.org/10.3390/IECF202007768

Academic Editors: Angela Lo Monaco, Cate Macinnis-Ng and Om P. Rajora

Published: 10 November 2020

Publisher's Note: MDPI stays neutral with regard to jurisdictional claims in published maps and institutional affiliations.

Copyright: (C) 2020 by the authors. Licensee MDPI, Basel, Switzerland. This article is an open access article distributed under the terms and conditions of the Creative Com-mons Attribution (CC BY) license (http://creativecommons.org/licenses /by/4.0/).

\begin{abstract}
Cable-based technologies have been a backbone for harvesting on steep slopes. The planning of a cable road is a complex task. It essentially comprises the definition of the start and end points of a cable road, as well as the intermediate supports. It must be ensured that the permissible forces (in particular, skyline tensile forces) are not exceeded, that there is a sufficient clearance between the load path and the ground, that suitable anchor trees are found, and that at the same time the number of intermediate supports is minimized as far as possible. On the other hand, for ergonomic and silvicultural reasons (work safety, damages to the forest), the skyline should be as high as possible. In practice, the search for a solution is often iterative; especially with long lines, several attempts may be necessary until a good line is found. The presented QGIS (free and open-source crossplatform desktop geographic information system) plugin searches automatically for the optimal cable road layout, so the planning process can be considerably simplified and obtained solutions are more cost-efficient. The plugin is designed for Central European conditions and assumes a standing skyline (fixed anchored skyline at both ends). For the calculation of the mechanical properties of the skyline, a close to catenary method is used (Zweifel 1960). When testing the feasibility of the cable line, care is taken that (1) the maximum permissible stresses in the skyline are not exceeded, (2) there is a minimum distance between the load path and the ground, and (3) when using a gravitational system, there is a minimum inclination in the load path. The newly developed method calculates the load path curve and the forces occurring in it more accurately than other tools available on the market. We further present a method to identify potential support and anchor trees directly from remote sensing data, which we aim to integrate in a further plugin. This ensures that there are effectively trees at the proposed intermediate positions and that the solution can be implemented in practice.
\end{abstract}

Keywords: ecosystem services; Cable Road; standing skyline; QGIS; single tree detection

Supplementary Materials: The following are available online at https://www.mdpi.com/26734931/3/1/103/s1. 